\title{
Cuerpos fantasmales en la urbe global
}

Angel Martínez-Hernáez ${ }^{\star}$

\section{RESUMEN}

La fluidez se ha convertido en metáfora de una sociedad contemporánea donde, paradójicamente, la única estabilidad descansa en lo efímero, donde las formas sociales cambian antes de que se sedimenten. No obstante, en la urbe global entendida como espacio de flujos cristalizan algunas relaciones sociales - por ejemplo, el vínculo consumidor-mercancía. Esta relación social propicia la creación de una subjetividad corporalizada donde el cuerpo se ha convertido en un fin y no sólo en un medio. El cuerpo es aquí una doble entidad subjetivada (el cuerpo-consumidor) y objetivada (el cuerpo-mercancía), un ente fantasmal que deviene funcional a la sociedad de consumo.

Palabras clave: cultura del consumo; sociedad líquida; globalización; cuerpo; modernidad.

\section{Ghostly Bodies in the Global City}

\begin{abstract}
Liquidity has become a metaphor for a contemporary society in which, paradoxically, the only stability lies in the ephemeral; social forms and identities change too quickly to become sedimented. This article argues, however, that in the global city understood as a space of flows, certain social relations -for example, the link between consumer and commodity- have crystallized. This social, economic and political relation has favored the emergence of a corporeal subjectivity in which the body is not simply a means but an end in itself. The body is approached here as a dual entity that is at once both subjective (the consumer body) and objectified (the commodified body), a ghostly entity ideally adapted to and functional in consumer society.
\end{abstract}

Keywords: consumer culture; liquid society; globalization; body; modernity.

\footnotetext{
^ Professor Titular de Antropologia médica da Universitat Rovira i Virgili (Espanha) (www.urv. cat) e Diretor de Pesquisa da Área da Saúde do Institut d'Infància i Món Urbà (www.ciimu.org). Antropólogo e mestre em Psiquiatria Social e Epidemiologia. Professor Associado na Universidade de Barcelona (1995-2001) e Professor Visitante nas seguintes universidades: Universidade da Califórnia em Berkeley, Universidade de Perugia e Universidad Nacional Autónoma de México. Dirección: Departamento de Antropología - Universitat Rovira i Virgili - Campus Catalunya. Avinguda Catalunya, 35. 43002- Tarragona (ESPAÑA)

E-mail: angel.martinez@urv.cat
} 


\section{INTRODUCCIÓN: LA ESTABILIDAD DE LO INESTABLE}

El carácter líquido de la sociedad moderna y de su estilo de vida asociado se ha convertido en los últimos años en una metáfora recurrente en el paisaje intelectual de las ciencias sociales y humanas. Con tal tropo quieren evocarse imágenes de transformación social y fluidez, donde las formas de hacer y de estar cambian antes que se sedimenten, obligando a los ciudadanos de la modernidad a una reinvención constante de sus vidas y de sus identidades sociales; a la precipitación de lo inestable. El cambio continuo es el referente de lo estructural en la sociedad líquida, mientras que los saberes y prácticas con pretensión de estabilidad se convierten en fantasmagorías que son desechadas antes que puedan tomar cuerpo. La fluidez de la modernidad resignifica los horizontes antes de que hayan sido definidos con claridad y arroja a los actores sociales, como indica Bauman (2006) con acierto, a un yo permanentemente impermanente, completamente incompleto, definidamente indefinido y auténticamente inauténtico.

El ciudadano de la urbe global muestra, efectivamente, algunas de estas características que dibujan un prototipo social de subjetividad ligada al hedonismo de lo efímero. Esto no significa que hayan desaparecido las inercias que unen a los individuos a un mundo que también genera sus reiteraciones, sino que el principio predominante que rige ahora las existencias parece ser la estabilidad de lo inestable. Antes que la vida social cristalice, o justo después, ésta vuelve a buscar acomodo en otro tipo de estado, vuelve a reinventarse y transformarse. Es como si la definición que la física nos brinda de los estados sólido y líquido de la materia adquiriese una extremada fuerza evocativa para definir nuestro tiempo; entendiendo el primero, la solidez, como aquel que se basa en un movimiento entre sus moléculas muy restringido y limitado a una especie de vibración en torno a una posición de equilibrio fija, y el segundo, la liquidez, como aquel que permite que sus moléculas se encuentren relativamente libres y puedan cambiar su posición respectiva. La modernidad líquida introduce un grado considerable de entropía. Si como una vez dijo Clifford Geertz (1973), toda cultura organiza la experiencia de sus miembros poniendo a su alcance significados y haces de significados, el ciudadano de la urbe global se ve abocado a construir su proyecto vital a partir de sistemas de valores y representaciones que lejos de ser estáticos están marcados por la ductilidad, la hibridación cultural, la complejidad, la innovación, la provisionalidad y también la incertidumbre.

El propósito de este artículo es debatir cómo en la modernidad fluida se establecen también mecanismos de reiteración que permiten algunas cristalizaciones. Más concretamente, mi argumento es que el ciudadano de la urbe global aparece ligado a la relación consumidor-mercancía de una forma diferente a la establecida en el pasado, por ser este vínculo ahora vertiginoso y a la vez omnipresente. Esta relación social, que es además lazo económico-político y cultural, conforma una subjetividad que tiende a amagar los desarreglos sociales y a representarlos en un lenguaje naturalizado que apela al cuerpo más que al discurso. Es una de las características del nuevo individualismo y su énfasis en el cuerpo como agente hedonista y en las tecnologías corporales como promesas de reversibilidad 
corporal (el fitness, la cirugía plástica, la prolongación artificial de la juventud, etc.) y de felicidad (la cosmética corporal y psicofarmacológica, entre otras). El cuerpo es ahora una doble entidad fantasmal que es subjetivada (el cuerpo-consumidor) y objetivada (el cuerpo-mercancía), a la par que adquiere sintonía con la sociedad de consumo. Pero antes de entrar en este orden de cosas es preciso que aquí intentemos desentramar, aunque sea someramente, las condiciones que han posibilitado la construcción social de esta nueva subjetividad.

\section{LA GLOBALIZACIÓN Y EL VÉRTIGO}

Una mirada desapasionada a la dimensión histórica nos devuelve la imagen de una vida social que va tomando velocidad, al menos desde el advenimiento de la modernidad occidental entre los siglos XVII y XVIII (PRAT, 2007), y que exacerba su celeridad en los últimos decenios de la mano de los procesos de globalización. No por casualidad postmodernidad (GIDDENS, 1990), sobremodernidad (AUGÉ, 1993) e hipermodernidad (LIPOVETSKY, 2006) son algunos términos frecuentados para definir esta situación contemporánea. La famosa dicotomía que nos ofreció Lévi-Strauss (1996) entre "sociedades frías" - donde la tradición se reproduce a sí misma, sin cambios substanciales- y "sociedades calientes" -aquellas que transforman la reproducción en una especie de espiral, quién sabe si ascendente o descendente- adquiere capacidad denotativa y asociativa con la solidez y la liquidez, respectivamente. Frente a la circularidad que se reproduce sobre sí misma insistiendo en consolidar la tradición y el mundo social, las "sociedades calientes" imponen una fluidez que los procesos de globalización han exacerbado y acelerado.

La "globalización" o "mundialización" -si se prefiere la acepción francesa- ha sido definida como un proceso eminentemente tecnológico y económico, aunque también social, político, militar y cultural, que ha producido una interdependencia regional y una condensación del mundo hasta ahora inéditas. Para algunos escépticos se trata de una quimera que es fruto de un exceso intelectual (HIRST; THOMPSON, 1996). Para otros, en cambio, es un concepto que define una realidad objetiva, un nuevo pliegue del capitalismo, llámese "era global" (ALBROW, 1996), "era de la información" (CASTELLS, 1998) o exacerbación de la modernidad (GIDDENS, 1990). Los detractores de la globalización como realidad objetiva son cada vez más residuales, mientras los defensores de la validez empírica de este concepto han efectuado aportaciones diversas, a menudo penetrantes, sobre el mundo que nos toca vivir.

Los teóricos de la globalización suelen coincidir en que ésta muestra diferentes dimensiones, tanto en su infraestructura (la tecno-economía mundo, las migraciones transnacionales, generalmente organizadas desde el Sur hacia el Norte, la crisis ecológica, etc.) como en su superestructura (protagonismo de los mass media, incremento de las organizaciones políticas panestatales, metacultura global, etc). Una de ellas - probablemente la más propugnada- es que la internacionalización del capital y el poder de determinación de las redes de mercado transnacionales están conformando una economía-mundo caracterizada 
por la multiplejidad de las relaciones y por la consiguiente pérdida de poder de las estructuras estatales. Ciertamente, el Estado-nación es hoy más que nunca una entidad vulnerable a las estructuras financieras internacionales. Unas estructuras que se caracterizan por su volatilidad y su impredecibilidad (CHESNAIS, 1994; CASTELLS, 1998; HELD et al., 1999). Cuanto más líquidos (HELD, 2000) y desterritorializados son los mercados, más el Estado-nación se revela como una institución disfuncional, pues se muestra como demasiado pequeña para afrontar los retos de la globalización y -paradójicamente- demasiado grande para dar cuenta de los desafíos locales. De ahí la intensificación que se ha producido recientemente tanto de las políticas y estructuras pan-estatales como de la descentralización del poder en el interior de muchos estados.

Otra de las dimensiones más destacadas es la revolución tecnológica de tipo informacional que ha llevado a transformar las concepciones clásicas de espacio y tiempo o, si se prefieren las palabras de un autor como Castells (1998, p. 384): "la sustitución de los lugares por el espacio de los flujos y la aniquilación del tiempo por el tiempo atemporal". Y es que si el espacio tradicional se basaba en una coincidencia entre simultaneidad y contigüidad, dando preeminencia al "lugar" sobre lo global, ahora el espacio se estaría organizando, al menos para los procesos hegemónicos de producción, poder, cultura e interacción organizativa, en términos de flujos que superan el principio de contigüidad. Como indica Giddens (1990), la exacerbación de la modernidad ha supuesto la diferenciación progresiva entre el espacio (space) y el lugar (place). Este nuevo espacio se imbrica con un nuevo tiempo reconstituido que ha dejado de ser lineal, irreversible y predecible, para ser "deslocalizado", ahistórico y aleatorio, en el sentido de introducir discontinuidades en su secuenciación que hacen que pasado, presente y futuro puedan fragmentarse y recomponerse en un sistema virtual de "impulsos electrónicos" (CASTELLS, 1998)

La urbe global no es otra cosa que el nuevo espacio de los flujos. No es la ciudad como lugar (DELGADO, 2001). Es la sociedad como red de relaciones de todo tipo que va constituyendo una malla densa con posiciones de centralidad y de periferia, de globalización y desglobalización, de dominación y exclusión. La urbe global es una estructura de flujos que fagocita áreas hasta hace unas décadas consideradas rurales por oposición a lo urbano, que escapa a la materialidad de la ciudad para esparcirse y diseminarse, para desterritorializarse y alcanzar cualquier localidad. Esto no significa que el mundo local haya desaparecido. Como dice Castells (1998), si bien la mayor parte del poder se organiza en el espacio de los flujos, la gente sigue viviendo en los lugares. Las experiencias cotidianas continúan insertándose en las relaciones cara a cara, en las identidades étnicas y nacionales, en los sistemas de parentesco y en los vínculos de la afectividad.

A mi modo de ver, es como si la dicotomía entre comunidad (Gemeinschaft) y sociedad (Gesellschaft) que organizó durante tanto tiempo la división entre, por un lado, las relaciones a pequeña escala y, por otro, la vida ciudadana característica del modelo urbano-industrial (TÖNNIES, 1984), se hubiese desintegrado con la introducción de una tercera forma organizativa: la sociedad red. Ya no estamos ante una realidad social compleja - de solidaridad orgánica, 
como apuntaba otro clásico: Durkheim (1982) - que se solapa sobre el modelo de la comunidad basado en la solidaridad mecánica de la vida social a pequeña escala. Sobre estos dos prototipos se superpone una sociedad red articulada bajo el principio de la interconexión.

La superposición de la sociedad red sobre los modelos tradicionales de organización social no debe entenderse como una simple cohabitación, sino como una estructura que establece una lógica de dominación sobre las formas anteriores, ya sea mediante la coerción directa o la hegemonía de los "globalismos" (léase: ideologías de la globalización). Prueba de ello es que lo global acaba de una u otra forma localizándose e incidiendo en la vida de personas concretas mediante la tecnología, la economía, el poder militar o las tendencias culturales predominantes. Difícilmente se puede escapar en la urbe global o en sus márgenes al poder de los medios de comunicación, a los sistemas expertos como la biomedicina o a la miríada de marcas comerciales que conforman ese nuevo panteón de las compañías multinacionales. Incluso en los espacios más periféricos de la urbe global nos encontramos con cualquiera de estos sistemas y sus productos asociados: telenovelas, anuncios, marcas comerciales, medicamentos, entre otros muchos, que intentan persuadir a un consumidor potencial. Ahora bien, si todo lo global se localiza, no todo lo local se globaliza. No todo lo local es apropiado ni considerado apropiable. No todo es incluido en circuitos globales de comunicación y consumo.

El desprendimiento de lo local o, dicho de otra forma, la inclusión de productos locales en estructuras globales no es algo nuevo, pues tiene como referente histórico previo la época colonial europea, entre otros procesos de dominación económica y política precedentes. Lo novedoso ahora es la intensificación de este fenómeno. Las redes de interdependencia entre lugares diversos han acrecentado su densidad configurando un efecto de empequeñecimiento del espacio que revierte en el contacto entre culturas y en la asimilación y difusión de categorías, artefactos, ideas y productos diversos.

La urbe global ha supuesto una ruptura progresiva con el esquema clásico que identificaba cultura con territorio. Esto no significa que se esté produciendo una modificación total de las adscripciones territoriales a las cuales han estado vinculadas la mayoría de las culturas existentes, sino que se observa un mayor desprendimiento de las culturas del "lugar" y una mayor desterritorialización, diseminación e interacción intercultural que tiene como paradigma la ciudad multicultural. Hannerz $(1993,1996)$ lo ha definido como una especie de "ecumene global" donde las diferentes culturas están adquiriendo gradualmente el papel de subculturas. A mi juicio, la urbe global propicia una metacultura que disimula, mediante el collage de la diversidad cultural, una realidad de mestizaje e hibridación desiguales, así como de hegemonía. La urbe global es más una red que una ecumene, más un escenario de mercado y dominación que una realidad de comunicación entre iguales. 
Si nos preguntamos ¿cómo los diferentes productos culturales consiguen su inclusión en la red de flujos transnacionales?, la respuesta que parece más razonable es: mediante su reconversión a la estructura que hace posible la globalización; y ésta es principalmente la tecnoeconomía-mundo, entendida en un sentido amplio e inclusivo de los medios informacionales y de comunicación. Adicionalmente, vale la pena especificar que hablar de tecnoeconomía mundo no significa limitar la naturaleza de esta estructura a un ámbito puramente material. Todo sistema económico y productivo está constituido a partir de lógicas y sistemas ideacionales que implican normatividades, representaciones y planificaciones. Como ha apuntado Godelier (1989, p. 165), hasta en el núcleo duro de las fuerzas productivas de las sociedades, en el corazón más material de las infraestructuras, encontramos siempre una dimensión ideal que "constituye una especie de armadura, un esquema organizador interno de su puesta en práctica". La estructura tecnoeconómica que posibilita la interdependencia regional no es una excepción a esta regla.

El protagonismo de la tecnoeconomía-mundo en los procesos de difusión cultural supone la reconversión de los productos culturales, sean éstos comida china, tallas de madera senegalesa, canciones norteamericanas o terapias asiáticas tradicionales, en mercancías. De este modo, los productos y significados culturales locales quedan insertados en estructuras significantes globales que los modifican, absorben y trasladan a una variedad de usuarios/consumidores de otras latitudes, los cuales los transforman y refuncionalizan de acuerdo con sus propias necesidades; aunque, todo hay que decirlo, muchas de estas necesidades pueden venir impuestas por la lógica estructural global o ser el resultado de la eliminación por parte del mercado de los productos locales rivales. De este modo, las realidades locales guardan un grado importante de supeditación a la estructura de los procesos de globalización. Incluso podemos pensar que los nuevos movimientos contestatarios y de revitalización de las culturas indígenas se ven abocados a participar de esta misma estructura, pues ella es la arena del poder económico y político de la modernidad. Es por ello que los productos culturales que nos llegan de otros mundos locales -aunque quizá la palabra "mundo" tenga una excesiva connotación de autonomía- aparecen generalmente reconvertidos en mercancías, o en noticias, que son hoy en día un tipo más de mercancías.

En este contexto, la modernidad occidental - llamémosla sistema postindustrial, nuevo capitalismo, capitalismo informacional o, siguiendo los pasos de Max Weber (1987), "racionalización" capitalista- revela dos de sus facetas más destacadas. Por un lado, se hace visible en un conjunto de productos, servicios, modas, tendencias y modelos culturales que son mercantilizados e insertados en flujos transnacionales. Por otro, y aquí reside su poder, ella es la misma estructura material/ideacional de flujos y de mercado global que penetra en las diferentes lógicas regionales mercantilizando o desechando sus productos y "atrapando" a las estructuras locales mediante sistemas diversos de hegemonía y coerción.

La urbe global es fundamentalmente un mercado planetario que necesita autoconsumirse incesantemente para autorreproducirse. En ella, lo moderno se convierte en tradicional en un lapso breve de tiempo o se diluye como efímero 
antes de adquirir forma. También, paradójicamente, lo tradicional deviene en lo que podemos denominar como "pseudo-tradicional efímero", ya que en la modernidad líquida la tradición siempre es un espejismo esencializado como una realidad que fue, cuando nunca fue; no al menos de la misma forma ni cumpliendo las mismas funciones sociales. La culturas indígenas que antes hemos citado ya no son lo que eran, ni lo serán, pues deben reinventarse a sí mismas como consecuencia de estructuras globales que las aplastan y las obligan a una reacción y reconstrucción continuas. Ya se sabe, lo global no alcanza a todos en términos de oportunidades, pero sí a la mayoría en relación a sus constreñimientos. Tampoco son tradicionales los productos culturales etiquetados como tales a los que accede el ciudadano de la urbe global persuadido por el marketing de lo auténtico.

El ciudadano de la urbe global es, fundamentalmente, un consumidor cosmopolita que tiene un acceso como nunca se tuvo a productos de otros mundos locales; sin embargo, y de forma casi invariable, este acceso viene gobernado por la relación consumidor-mercancía como estructura significante. El contenido de los productos puede ser muy variado (gastronomía, ropa, arte, deporte, noticias, tecnologías de la comunicación). Su denominación de origen también, pues las compañías multinacionales se han constituido en una especie de nueva patria al lado de las históricas, con sus señas de identidad, su impronta, su estilo, su cultura empresarial y su imagen de marca. No obstante, la forma y las condiciones de acceso a estos productos son recurrentes y uniformes, pues se enraízan en el vínculo mercancía-consumo. ¿Significa esto que todo está mercantilizado en la modernidad? Evidentemente no, pues también existen los movimientos sociales y los espacios basados en la reciprocidad, en la ayuda mutua y en mecanismos semejantes que se esparcen y desterritorializan. ¿Significa esto que la lógica de la mercancía es hegemónica? Sí, por supuesto, y que esa misma lógica ha convertido la metacultura global en una cultura y una sociedad del consumo que organiza nuestras vidas y promueve una nueva subjetividad consumista. El riesgo de no adaptarse a este modelo de subjetividad es la marginación y la desafiliación ("modernizarse o morir", diría Bauman). El precio: la soledad del cuerpo fantasmal.

\section{Cuerpos fantasmales}

El exceso de información, de productos, de objetos consumibles, de modas y tendencias posibles es al paisaje de la urbe global como el ciudadano-consumidor es a su fantasmagoría de sujeto soberano con capacidad individual de decisión. La autonomía del consumidor debe ser creída por él mismo para que se convierta en funcional con una sociedad basada en la construcción continua de deseos, carencias y necesidades, así como de los productos adecuados para responder a estas insatisfacciones. Cada vez que una mercancía comienza a resolver una insatisfacción, aparecen otras nuevas frustraciones generadas en la comparación con nuevas mercancías del mismo orden o en las nuevas necesidades creadas a partir de su consumo. Así debe ser para que este modelo social se reproduzca constantemente ofreciendo promesas que nunca podrán ni deberán ser cumplidas, 
pues de eso se trata, de generar deseos que nunca puedan ser colmados, de poner a trabajar los estados de ánimo, las emociones y los recursos corporales en beneficio de determinados intereses de consumo.

La ilusión de autonomía del ciudadano de la modernidad viene asociada a la centralidad del cuerpo en nuestras vidas; un cuerpo que es ahora fin y no sólo medio. Está presente en los debates intelectuales y en la lucha política sobre la identidad sexual y de género, así como en la denuncia ciudadana de la violación, la tortura o el uso de artefactos como las minas anti-persona. Lo hallamos en ese imaginario evocado por biotecnologías como la fecundación asistida, la clonación, las técnicas de recombinación del $\mathrm{ADN}$ o la prolongación artificial de la vida; biotecnologías que - todo hay que decirlo - anuncian la superación de las fronteras corporales tradicionales y la posibilidad de rediseñar nuestra corporalidad. Adquiere también un papel destacado en las prácticas cotidianas, como son las nuevas rutinas basadas en la dieta y la gimnasia para la consecución de determinadas metas estéticas, así como en la cultura del consumo con su bombardeo de imágenes creadoras de necesidades y deseos corporales. El lugar que en otros momentos ocuparon categorías como "espíritu", "ciudadano", "personalidad" o "sujeto" ha sido ahora ocupado por esta entidad socionatural que condensa las nuevas tensiones del ciudadano de la urbe global.

Para algunos autores, como Terence Turner (1994), la centralidad del cuerpo no es otra cosa que el reflejo del individualismo consumista del capitalismo tardío que ha tendido a localizar en una dimensión socialmente sagrada (el cuerpo) un conjunto de construcciones culturales como la identidad y de fenómenos sociales como las relaciones de producción. El cuerpo y sus derivados (corporalidad, incorporación, embodiment, etc.) son, en realidad, conceptos profusamente utilizados en las ciencias sociales, en la crítica de arte y en esos nuevos discursos humanísticos que son los estudios culturales. Quizá, como también indica Turner, esto no sea más que la expresión de cómo el nuevo capitalismo ha determinado los discursos profanos e intelectuales de nuestro tiempo, incluyendo las formas de lucha política de la sociedad civil que desde la década de los sesenta reivindican el cuerpo como espacio de libertad individual. Pensemos a modo de ejemplo -y a pesar de que para algunos pueda ser herético - en el Mayo francés del 68 y sus slogans asociados a la libertad personal y a la autogestión del cuerpo como uno de lo hitos que anunciaba el paso de un capitalismo de la producción a un capitalismo del consumo, pues ¿acaso no sirvió para transformar el orden de las cosas, para crear nuevos consumidores "autónomos", para superar el encorsetamiento de un cuerpo como medio para redefinir un cuerpo como fin?

En nuestra "monocultura global de la felicidad" basada en la buena vida, la evitación del sufrimiento, el confort cotidiano y el consumo de la mayor cantidad posible de bienes y servicios (APPLBAUM, 2000), el cuerpo adquiere un especial protagonismo que nubla al sujeto del discurso y lo fagocita, convirtiéndolo en un sujeto fundamentalmente corporal. El cuerpo es ahora uno de los espacios privilegiados de consumo y uno de los objetos más frecuentemente mercantilizados para la creación de (in)satisfacciones y deseos. El cuerpo es agente activo del consumo (el cuerpo-consumidor) y a la vez mercancía (el cuerpo-consumido). El primero 
redunda en un individualismo hedonista y en la ilusión del "cuerpo subjetivado". El segundo, por su parte, bien puede asociarse con la fantasmagoría de un "cuerpo objetivado" en mímesis con la mercancía o actuando como su soporte.

La dialéctica entre subjetivación y objetivación del cuerpo nos evoca con facilidad conceptos muy frecuentados en la teoría marxista como fetichismo de la mercancía. También evoca la conocida afirmación de Marx (1976) en El capital con respecto a que el capitalismo supone tanto la cosificación de las personas y las relaciones sociales como la personificación de las cosas. El cuerpo-consumidor es un cuerpo subjetivado y personificado en beneficio de un sujeto reificado. Por su parte, el cuerpo-mercancía es un cuerpo objetivado y cosificado que actúa como soporte de una marca comercial que ha sido subjetivada y personificada. En ambos casos se descubre bajo estas dialécticas inversas el fenómeno que Lukács (1969) definió como objetivación del sujeto y subjetivación del objeto, así como una de las formas más expresivas de esta curiosa pirueta simbólica del capitalismo: la creación de una "objetividad fantasmal" por la cual el mundo de los fenómenos puede ser desocializado y desubjetivado en nombre de una presunta objetividad de hechos reales.

Como es sabido, la doble dialéctica de cosificación y personificación es propia de la lógica de la mercancía, pero esto no supone que no afecte a órdenes de realidad distintos; esto es: no directamente económicos, pues estos órdenes pueden estar indirectamente colonizados por esta misma lógica. Este es el caso de los sistemas expertos de la modernidad y sus burocracias asociadas de gestión de los cuerpos que actúan como estructuras estructuradas además de estructuras estructurantes, como diría Bourdieu (1991). El campo de la medicina occidental o biomedicina es un ejemplo palmario.

Sabemos que el papel reificador de la medicina no es algo nuevo. Como argumentó Michel Foucault (1974) en Naissance de la clinique, el fenómeno de la cosificación y fragmentación del cuerpo tiene uno de sus precedentes más destacados en la conformación, a principios del siglo XIX, de la medicina positiva. Comparando un informe clínico de Pomme, un clínico del siglo XVIII que trató de curar un caso de histeria con baños de diez a doce horas por día durante diez meses, y otra de Bayle, un médico del siglo XIX que visualizó por primera vez las lesiones encefálicas de la parálisis general progresiva sifilítica, Foucault (1974) nos introdujo en ese pliegue del conocimiento que dio luz a la medicina positiva. En un lapso inferior a cien años, en el intermedio de la medicina de finales del siglo XVIII y principios del XIX, se produjo una transformación tal de la ciencia médica que el modelo clasificatorio, externalista y neohipocrático de las enfermedades fue sustituido por una incursión sistemática en el espacio de los órganos. Como consecuencia de esta nueva articulación o episteme, el conocimiento médico se desplazó de una botánica de los síntomas a una gramática de los signos, de una visión holística de la enfermedad y del cuerpo a una perspectiva fragmentada, de un “¿Qué tiene usted?” a un “¿Dónde le duele a usted?”. 
Los rasgos que trazó Foucault sobre el nacimiento de la medicina positiva son aplicables al desarrollo posterior de la ciencia médica, que ha ido perfeccionando progresivamente tanto el proceso de reificación del cuerpo como el aura de objetividad fantasmal de su conocimiento y de su práctica. La estructuración de la medicina en especialidades que se corresponden con determinados fragmentos o estructuras del cuerpo, la proliferación de técnicas de imaginería que permiten la visualización del espacio de los órganos y el impacto más reciente de la biología molecular y sus biotecnologías asociadas, son algunos ejemplos de reificación. También las prácticas cotidianas en los sistemas expertos. En el hospital, los médicos y otros profesionales de la salud conversan entre sí sobre la patología del número siete, o del quince, hablan entre sí sobre la fatiga de final de jornada tras haber tenido "tres fémur y dos epifisiólisis", o relatan que han asistido "tres neoplasias y dos cirrosis hepáticas". En el lenguaje médico, el "dónde" que apuntaba Foucault se ha convertido en el espacio protagonista. El sujeto que habita el cuerpo, ese sujeto que se llama "yo" en el discurso y que adquiere entidad biográfica, ha sido disuelto y omitido. Sus palabras se corresponden, en todo caso, con una comunicación de malestares, síntomas y signos de alguna enfermedad o disfunción (MARTÍNEZ-HERNÁEZ, 2000). Ahora, el mundo experiencial y biográfico del afligido requiere sólo una atención anecdótica que se observa como algo propio del trato "humano" o "humanitario", pero no como aquello que debe centrar la atención del profesional. El cuerpo ha sido reificado, naturalizado y resignificado en otra entidad nueva que será gestionada con racionalidad burocrática. Pero no sólo eso.

En realidad, en el discurso médico observamos una doble resignificación. El paciente es naturalizado y objetivado mientras su enfermedad es personificada. Es lo que se desprende de frases como "Hoy he tenido tres neoplasias", donde el paciente ha sido cosificado y encapsulado en la realidad natural de una enfermedad inevitable cuya lógica es desocializada y, en cambio, la patología adquiere carácter de personaje con vida propia en el imaginario del discurso médico. De esta manera se construye una objetividad fantasmal que aísla la enfermedad del sujeto y de sus relaciones sociales. Poco importa el papel de la pobreza, de la marginación social, de la opresión, de las dietas empobrecidas, de los agrotóxicos, de las campañas publicitarias de substancias cancerígenas o de la polución. Una neoplasia es siempre una neoplasia.

En los mensajes publicitarios ocurre algo parecido. El cuerpo es objetivado y cosificado como mercancía o soporte de la mercancía. Sin embargo, el producto cosmético, el perfume, el pantalón de moda o el alimento rico en fibras que promete una larga vida a su consumidor son realidades personificadas que se convierten en protagonistas del relato. Lo que tiene personalidad propia, lo que tiene un nombre, no es el cuerpo, sino el producto que representa. Incluso en aquellas circunstancias en las que las mercancías son presentadas por rostros famosos, lo significativo de esos rostros es que ya son un producto en el mercado (una mercancía) que avala los beneficios del objeto o servicio anunciado. Estamos ante una marca comercial presentando otra marca comercial. El cuerpo de la publicidad es, en realidad, un cuerpo cosificado, anónimo y en soledad que 
adquiere personificación sólo en la medida en que se mercantiliza, en que toma una decisión que se presenta como inteligente, en que maximiza su capital, en que viste una prenda con nombre que le convierte en alguien con capacidad de consumo o con signos identitarios dentro de la cultura de la modernidad.

Probablemente no haya otra cultura que haya sacralizado el cuerpo de la misma forma que la metacultura global contemporánea El cuerpo es el paradigma del nuevo sujeto en la también nueva sociedad, pues enfatiza las características más funcionales de consumo continuado e irreflexivo. Es evidente que el cuerpo está anudado a un sujeto social que toma decisiones o que cree tomarlas, pero de lo que se trata ahora es que este sujeto es sobre todo un cuerpo fantasmal o -quizá sería mejor decir- una corporalidad fantasmal.

El cuerpo es material, obviamente, pero también es cultural. Como indica Csordas (1994) en su defensa de una antropología del (o desde el) embodiment, hay una diferencia substantiva entre el cuerpo como materialidad y la corporalización (embodiment) como realidad social. De igual forma que no es lo mismo la base física de un libro y el texto que ésta incorpora, tampoco lo es el cuerpo material y el cuerpo como agente activo y culturalmente construido. Esta esencia biocultural de lo corporal es la que posibilita el anudamiento entre necesidad y significado, a la vez que permite que ese mismo anudamiento pueda reproducir mediante la necesidad del sentido y el sentido de la necesidad estructuras como la sociedad de consumo. No existiría una sociedad de consumo sin cuerpos consumidores ni cuerpos consumidos generadores de deseos y necesidades. Cuerpos, también, solitarios. El cuerpo ante el televisor consumiendo mensajes publicitarios construidos a partir de otros cuerpos o fragmentos corporales, el individuo-consumidor haciendo uso de las nuevas tecnologías, el cuerpo bulímico o anoréxico interiorizando, incorporando y consumiendo determinados cánones estéticos, o el sujeto abatido e insomne que transforma la tristeza en una "depresión" que "debe" ser asistida con los antidepresivos de última generación, son todas ellas imágenes de soledad.

La omnipresencia del cuerpo en la urbe global puede entenderse como una hipertrofia del individualismo en el capitalismo tardío. El sujeto del discurso ha dejado paso a la hegemonía de un cuerpo objetivado-subjetivado como símbolo y función indispensable de la nueva sociedad de consumo; un modelo corporal que muestra pretensiones de universalidad, ya que se esparce en el espacio/tiempo de los flujos creando tendencias, deseos, necesidades y empatías. Es una de las múltiples paradojas de nuestro tiempo, pues cuanto más diversos y autónomos nos pensamos a nosotros mismos en nuestra capacidad para diseñar nuestras vidas, más inmersos nos encontramos en los enredos de un juego social que genera homogeneidades y nuevos constreñimientos, como el hedonismo ávido y la soledad encastillada del consumidor.

El elemento distintivo de la modernidad no se encuentra, obviamente, en el consumo como acción universal humana, sino en el tipo de consumo, en eso que Bauman (2006, p. 110) ha llamado con acierto "síndrome consumista" que prima, a diferencia de la sociedad productivista del capitalismo pre-informacional, la ra- 
pidez, el exceso y el desperdicio. Dicho en otras palabras, el síndrome consumista ha reducido el intervalo para la resolución de la insatisfacción (la rapidez), ha multiplicado el número de necesidades e insatisfacciones (el exceso) y ha generado un estilo de vida basado en la consecución de productos que rápidamente se convierten en descartables y efímeros (el desperdicio). Estas tres características del síndrome consumista son, a mi juicio, inherentes a la nueva subjetividad corporal: a) el cuerpo ávido y ansioso por consumir, b) el cuerpo del exceso que se expresa en la obesidad y también en la dialéctica entre anorexia y bulimia, y c) el cuerpo descartable, modificable y líquido que trata de evacuar el exceso previo con un nuevo consumo, con la fantasía de una carencia (in)satisfecha.

\section{A MOdo De CONCLuSIÓN}

La imagen típica del capitalismo productivista: la gran fábrica con obreros "incorporando" las tareas productivas hasta reproducirlas como espasmos, como nos representaba de forma aguda, cómica y a la vez desgarrada Chaplin en Tiempos modernos, o la transposición macabra de la gran fábrica a los campos de exterminio, como en Auschwitz, ha dejado paso en el capitalismo del consumo a una nueva imagen constituida por el cuerpo en soledad, el cuerpo aislado, el cuerpo individual enmudecido que se muestra como objeto de deseo, como anuncio ambulante de prendas de moda o como expresión de una experiencia más inscrita en surcos, gestos, tatuajes y miradas que en palabras. Esta nueva imagen resulta más acorde con la deslocalización productiva y con las pautas de consumo de la modernidad, pues son experiencias de soledad reconvertidas en mercancías de consumo para otras experiencias de soledad. Su formato más común, y probablemente más paradigmático, es la imagen del cuerpo solitario de los spots publicitarios de perfumes y productos cosméticos, donde se prima la individualidad corporal a partir del recurso iconográfico de una emocionalidad autocontenida en el lenguaje hablado, pero no en el corporal. Evocaciones de experiencias que son diseñadas con iconos mudos que producen un efecto de aislamiento y, curiosamente, de empatía desde su aislamiento, donde los personajes secundarios suelen convertirse en un paisaje naturalizado y deshumanizado. $\mathrm{La}$ intimidad del cuerpo resalta en este contexto como la hipérbole del individualismo, como la ilusión de una experiencia aislada y autoconstruida a partir de imágenes, de recuerdos, de sensaciones, de evocaciones, de sentimientos y de sensibilidades interiores. Incluso el cuerpo en acción, en movimiento, en interacción, tiende a minusvalorar el ambiente externo, pues las escenografías son puestas en escena desde y para el cuerpo protagonista, de la misma manera que el objetivo final es acceder a otros cuerpos anónimos, desconocidos y solitarios, al margen de cual sea su localización y su historia. 


\section{REFERENCIAS}

ALBROW, M. The Global Age: State and society beyond modernity. Cambridge: Polity, 1996.

APPLBAUM, K. Crossing borders: globalization as myth and charter in american transnational consumer marketing. American Ethnologist, v. 27, n. 2, p. 257-282, 2000 .

AUGÉ, M. Los nos lugares espacios de anonimato: una antropología de la sobremodernidad. Barcelona: Gedisa, 1993.

BAUMAN, Z. Vida líquida. Barcelona: Paidós, 2006.

BOURDIEU, P. El sentido práctico. Madrid: Taurus, 1991.

CASTELLS, M. La era de la información: economía, sociedad y cultura. Madrid: Alianza, 1998. v. 3.

CHESNAIS, F. La mondalisation du capital. París: Syros, 1994.

CSORDAS, T. J. Embodiment and experience. Cambridge: Harvard University Press, 1994.

DELGADO, M. Los procesos de apropiación del espacio público: etnografía de los espacios urbanos. In: PROVENSAL, D. Espacio y territorio: miradas antropológicas. Barcelona: Universitat de Barcelona, 2001. p. 45-54.

DURKHEIM, E. La división del trabajo social. Madrid: Aka, 1982.

FOUCAULT, M. Naissance de la clinique. París: PUF, 1974.

GEERTZ, C. The interpretation of cultures. New York: Basic Books, 1973

GIDDENS, A. The consequences of modernity. Stanford: Stanford University Press, 1990.

GODELIER, M. Lo ideal y lo material: Madrid: Taurus, 1989.

HANNERZ, U. Cultural complexity: studies in the social organization of meaning. New York: Columbia University Press, 1993. 1996.

Transnational connections: culture, people, places. Londres: Routledge, 
HELD, D. ¿Hay que regularizar la globalización?. Claves de razón práctica, Madrid, n. 99, p. 4-11, 2000.

HELD, D. et al. Global transformations: politics, economics and culture. Cambridge: Polity, 1999.

HIRST, P.; THOMPSON, G. Globalization in question: the international economy and the possibilities of governance. Cambridge: Polity, 1996.

LÉVI-STRAUSS, C. Raza y cultura. Madrid: Cátedra, 1996.

LIPOVETSKY, G. Los tiempos hipermodernos. Barcelona: Anagrama, 2006.

LUKÁCS, G. Historia y conciencia de clase: estudios de dialéctica marxista. Ciudad de México: Grijalbo, 1969.

MARX, K. Capital: a critique of political economy. London: Penguin Books, 1976. v. 3.

MARTÍNEZ-HERNÁEZ, A. What's behind the symptom? London: Routledge, 2000 .

PRAT, J. Los sentidos de la vida: la construcción del sujeto, modelos del yo e identidad. Barcelona: Bellaterra, 2007.

TIEMPOS modernos. Producción: Charles Chaplin. Director y guionista: Charles Chaplin. Estados Unidos: United Artists, 1936. Formato 1'33.

Duración 87 minutos.

TÖNNIES, F. Comunitat i associació. Barcelona: Edicions 62, 1984.

TURNER, T. Bodies and anti-bodies: flesh and fetish in contemporary social theory. In CSORDAS, T. (Ed.). Embodiment and experience. Cambridge: Harvard University Press, 1994. p. 27-47.

WEBER, M. Economía y sociedad. México: Fondo de Cultura Económica, 1987.

Recebido em: junho de 2009

Aceito em: julho de 2009 